\title{
ASSÉDIO MORAL E GÊNERO NA UNIVERSIDADE PÚBLICA: RESSONÂNCIAS DO PRODUTIVISMO NO TRABALHO DOCENTE
}

\section{ACOSO MORAL Y GÉNERO: RESONANCIAS DEL PRODUCTIVISMO ACADÉMICO EM EL TRABAJO DOCENTE}

\section{MORAL HARASSMENT AND GENDER IN THE UNIVERSITY: RESONANCES OF PRODUCTIVISM IN TEACHING WORK}

\author{
Vanessa Catherina Neumann FIGUEIREDO ${ }^{1}$ \\ Quezia Eloise França da SILVA ${ }^{2}$ \\ Franciele Ariene Lopes SANTANA ${ }^{3}$
}

RESUMO: Este estudo rastreou indícios de assédio moral em uma universidade federal brasileira, buscando identificar situações ofensivas sofridas por homens e mulheres. Foi aplicado o Questionário de Atos Negativos-Revisado e um formulário sociodemográfico e ocupacional em 35 professoras e 41 professores. A análise dos eventos e frequências assinaladas permitiu verificar que entre os 76 participantes $38,2 \%$ sofreram assédio moral $(15,7 \%$ mulheres e $22,5 \%$ homens) e $15,8 \%$ foram alvo de agressões pontuais/violência psicológica $(11,9 \%$ mulheres e 3,9\% homens). Não foi encontrada preponderância de gênero entre os agressores, indicando uma cultura organizacional marcada pela ideologia da virilidade. Colegas na mesma condição hierárquica foram os principais perpetradores. A discrepância entre a percepção subjetiva de ter sido alvo de assédio (60\% mulheres e $47,8 \%$ homens) e a análise dos atos negativos demonstra a necessidade de acolhimento e de políticas organizacionais de enfrentamento da violência no trabalho.

PALAVRAS-CHAVE: Assédio moral. Gênero. Universidade pública.

RESUMEN: Este trabajo rastreó señales de acoso moral en una universidad federal brasileña, identificando situaciones ofensivas sufridas por hombres y mujeres. Se aplicó el Cuestionario Revisado de Actos Negativos y un formulario sociodemográfico y ocupacional a 35 profesoras y 41 profesores. El análisis de las situaciones y frecuencia indicados permitió constatar que de los 76 participantes el 38,2\% sufrió acoso moral (15,7\% mujeres y 22,5\% hombres); 15,8\% fueron objeto de agresiones específicas/violencia psicológica (11,9\% mujeres y 3,9\% hombres). No hubo preponderancia de género entre los agresores, lo que indica una cultura organizacional marcada por la ideología de la virilidad. Los compañeros en la misma condición jerárquica fueron los principales agresores. La discrepancia entre la percepción

${ }^{1}$ Universidade Federal de Mato Grosso do Sul (UFMS), Corumbá - MS - Brasil. Professora Associada nos Programas de Pós-Graduação em Educação, e de Estudos Fronteiriços e no curso de Psicologia. Doutorado em Saúde Coletiva (UNICAMP). ORCID: http://orcid.org/0000-0002-0062-9234. E-mail: vanessa.figueiredo@ufms.br

${ }^{2}$ Universidade Federal de Mato Grosso do Sul (UFMS), Corumbá - MS - Brasil. Acadêmica no Curso de psicologia. ORCID: http://orcid.org/0000-0001-5257-1612. Email: qeloise@gmail.com

${ }^{3}$ Universidade Federal de Mato Grosso do Sul (UFMS), Corumbá - MS - Brasil. Psicóloga do Serviço de Psicologia e Acessibilidade Pedagógica - SEPAP/CPAN. Mestrado em Educação (UFMS). ORCID: http://orcid.org/0000-0002-3931-1493.E-mail: franciele.santana@ufms.br

RPGE- Revista on line de Política e Gestão Educacional, Araraquara, v. 24, n. esp. 3, p. 1841-1855, dez. 2020. e-ISSN:1519-9029 
subjetiva de haber sido objeto de acoso (60\% mujeres y 47,8\% hombres) y el análisis de actos negativos demuestra la necesidad de politicas de acogida y organizativas para enfrentar la violencia en el trabajo.

PALABRAS CLAVE: Acoso moral. Género. Docencia. Universidad pública.

ABSTRACT: This study tracked signs of moral harassment at a Brazilian federal university, seeking to identify offensive situations suffered by men and women. The Revised Negative Acts Questionnaire and a sociodemographic and occupational form were applied to 35 female teachers and 41 male teachers. The analysis of the events and frequency indicated that among the 76 participants $38.2 \%$ suffered moral harassment (15.7\% women and $22.5 \%$ men) and $15.8 \%$ were the target of specific aggressions/psychological violence $(11.9 \%$ women and $3.9 \%$ men). There was no gender preponderance among the aggressors, indicating an organizational culture marked by the ideology of virility. Colleagues in the same hierarchical condition were the main perpetrators. The discrepancy between the subjective perception of having been subject to harassment $(60 \%$ women and $47.8 \%$ men) and the analysis of negative acts demonstrates the need for welcoming and organizational policies to face violence at work.

KEYWORDS: Moral harassment. Genre. Teaching. Public university.

\section{Apontamentos sobre a gestão das universidades públicas}

Alicerçado no ideário neoliberal, valores meritocráticos ligados ao produtivismo têm ganhado amplidão nas instituições públicas de ensino, adulterando a função social da universidade e o sentido do fazer. Com a disseminação do gerencialismo e do Estado mínimo, são forjados projetos e objetivos a serem alcançados pelos professores, mais adequados para a avaliação bem-sucedida do curso e da própria instituição.

É por meio do sequestro da subjetividade que se dá a submissão do desejo aos ideais da instituição. Mesmo com a crescente retirada de verbas destinadas à educação pública, materiais escassos, pessoal insuficiente e salário incongruente com as funções, observa-se a adesão dos docentes ao discurso de excelência e da competência para lograrem a métrica aplicada institucionalmente. Assim, para cumprirem com as exigências de publicação, participações em reuniões, bancas, comissões, aulas, cursos de extensão, recorrem ao aumento de jornada, com a invasão do serviço no âmbito doméstico e nos horários de lazer (GRAETZ, 2013; MOREIRA, 2009).

As medidas de regulação do trabalho criativo pautadas na racionalidade instrumental, cuja avaliação do desempenho compara e define a qualidade dos trabalhadores e das instituições de ensino, tem acarretado sobrecarga e intensificação do trabalho, rivalidade e alienação (SILVA; RUZA, 2018). A cultura organizacional competitiva, invadida pelos preceitos da 
qualidade total, acirra o individualismo, degrada a cooperação, compromete os laços éticos, propiciando o desmanche do coletivo e a formação de um espaço universitário patogênico e adoecedor.

Para ser possível trabalhar na desventura, o coletivo cria e compartilha estratégias que protegem a saúde mental por amenizarem ou refutarem o sofrer, sem a potência de ressignificar o trabalho. Contudo, o que se coloca em xeque é como o sistema organizativo agressivo induz a construção das estratégias, de maneira a forjar o assujeitamento à violência (DEJOURS, 2006; MENDES, 2007).

A exploração do individualismo (conduta de isolamento que favorece o silêncio e a sensação de impotência nas adversidades do trabalho, nos conflitos entre pares e desmantela o espírito de equipe), do cinismo viril (quando as maldades contra os outros são justificadas pela necessidade de demonstrar coragem e fortaleza), da negação (quando o indivíduo não reconhece a existência de situações desagradáveis em suas experiências, evitando perceber a realidade como ela é) e da servidão voluntária (atitude oriunda do entendimento de que o espaço de trabalho é inalterável, culminando, em uma atitude passiva frente às imposições e às possibilidades de transformação) diminui a capacidade de pensar, refletir e mudar os fatores geradores de ansiedade, aflição e solidão, degrada os laços solidários, banaliza as injustiças, as desigualdades, as práticas antiéticas e as condutas agressivas, conformando um contexto favorável à violência (DEJOURS, 2007; MEDEIROS; MARTINS; MENDES, 2017; MOREIRA et al., 2018)

Composta por atos hostis, ultrajantes e desrespeitosos, a patologia social da violência pode se manifestar física, sexual e/ou psicologicamente, nas verbalizações agressivas, na discriminação étnico-racial, no assédio sexual e no assédio moral. Diferente da impulsiva agressão pontual desprovida do desejo de aniquilar e do assédio moral organizacional, recurso perverso da autoridade, através da exposição, vergonha, ameaça, para o aumento da produtividade e obediência, no assédio moral interpessoal, a violação dos direitos humanos por atos abusivos, vexatórios, negligências e humilhações, corrompe os relacionamentos, é constante e duradoura. Objetiva prejudicar, afastar ou invalidar pessoas já previstas, tendo por resultado o abandono da profissão, a demissão, a transferência do local do trabalho ou a submissão ao poder (BARRETO; HELOANI, 2014; SOBOLL, 2008).

Indicador do extremo mal-estar que atinge o mundo laboral, o assédio moral é uma patologia organizacional sutilmente violenta com grande potencial de degradação das condições de trabalho, afetando consequentemente a saúde física e mental, decorrendo em quadros psicopatológicos de estresse pós-traumático, ansiedade, depressão (POOLI; 
MONTEIRO, 2018), sentimento de desamparo, desolação, abuso de álcool e drogas, ideação suicida, tentativas de tirar a própria vida (HELOANI; BARRETO, 2010; MONTEIRO et al., 2019).

Segundo Hirigoyen (2017), mesmo quando acontece de modo ascendente ou entre colegas, o assédio moral envolve uma relação assimétrica de dominação e subserviência forçada, cuja pessoa alvo dos abusos é desqualificada e achincalhada por conta de seu cargo/posição na estrutura hierárquica, incapacidades ou identidade de gênero. Levando em conta a histórica cultura patriarcal que embasa as relações de poder, compreender a estruturação do mercado de trabalho conforme as relações sociais de gênero mostra-se relevante para analisar a dinâmica da violência e as diversas situações de desigualdade de gênero materializadas na diferente valorização e alcance de espaços ocupacionais e prestígio por homens e mulheres (KERGOAT, 2009).

Nesta toada, com o objetivo de mitigar o assédio moral, a Organização Internacional do Trabalho (OIT, 2019) recomenda a adoção da Convenção 190 por parte dos países membros para a afirmação da intolerância à práticas abusivas especialmente contra mulheres, exigindo das instituições condenadas a elaboração de medidas preventivas, com indicações claras de direitos e obrigações dos agredidos e do empregadores, proteção dos denunciantes e avaliação dos riscos psicossociais do espaço laboral envolvendo a exposição à violência psicológica. Considerando a relevância do fenômeno e suas consequências a saúde docente e a educação, este estudo tem por objetivo rastrear os indicativos de situações de violência psicológica e assédio moral vivenciados por docentes universitários, conforme as relações de gênero e de poder existentes na instituição.

\section{Percurso Metodológico}

Foi realizado um estudo quantitativo, transversal, descritivo e exploratório junto a docentes de uma Universidade Federal localizada no centro-oeste brasileiro. O levantamento de dados se deu em 2018 e 2019, e todos os docentes em regime estatutário de um mesmo campus da instituição de ensino superior foram convidados a participar da pesquisa.

Na ocasião da aplicação dos instrumentos o campus possuía 13 cursos de graduação e 2 de pós-graduação stricto sensu. De um total de 105 docentes lotados na unidade, participaram $72,4 \%(n=76)$, sendo excluídos os que se encontravam em licença para capacitação ou tratamento de saúde, assim como aqueles que não compareceram no dia previamente agendado. Mediante assinatura prévia do Termo de Consentimento Livre e Esclarecido, os participantes 
receberam orientações sobre o estudo e de como preencher os instrumentos aplicados. O projeto de pesquisa foi aprovado no Comitê de Ética em Pesquisa em Seres Humanos da Universidade Federal de Mato Grosso do Sul sob o parecer no 2.519.776 (CAAE n. 82923818.3.0000.0021).

\section{Participantes}

Fizeram parte da pesquisa 41 homens e 35 mulheres, com média de idade de 42 anos para as mulheres (desvio padrão - DP 9,8) e 42,2 anos para os homens (DP 11,3), com estado civil e formação conforme na Figura 1:

Figura 1 - Tabela de participantes da pesquisa conforme o gênero

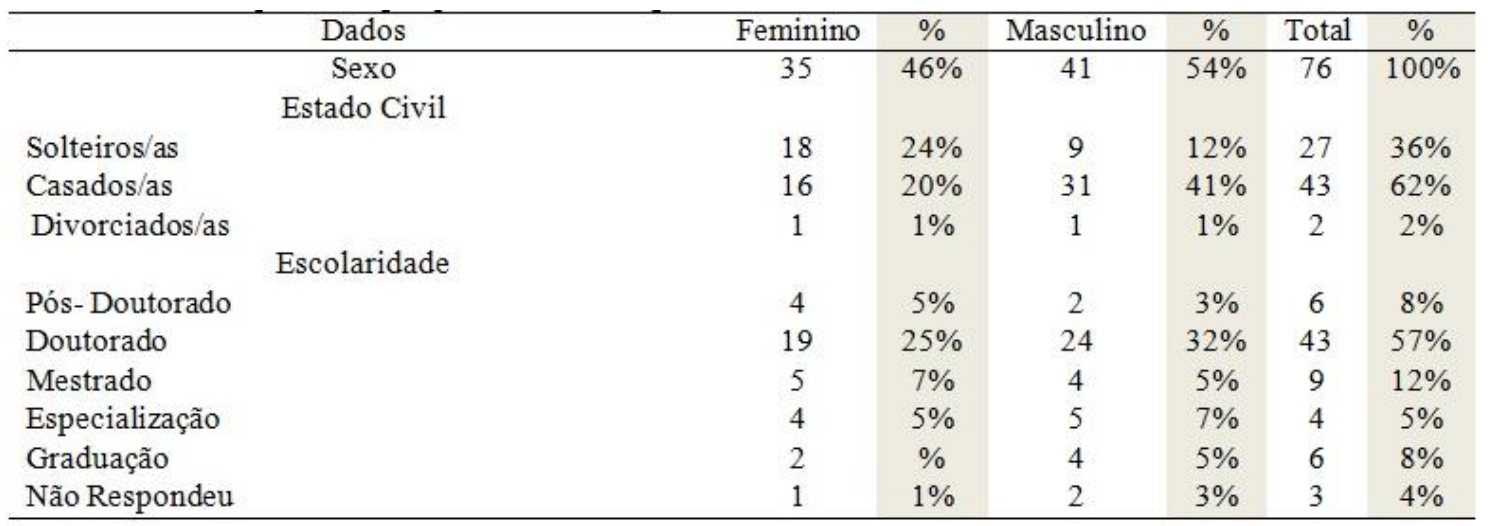

Fonte: Elaborado pelos autores

\section{Instrumentos}

Foram utilizados dois instrumentos auto-aplicáveis:

Questionário sociodemográfico e ocupacional contendo questões sobre escolaridade, estado civil, exercício no cargo de coordenação de curso, carga horária dedicada à graduação e pós-graduação, pesquisa, ensino, extensão, supervisão de estágios e de alunos em diversos projetos, orientação.

Negative Acts Questionnaire Revised (NAQ-R), instrumento criado em 1994 pelos noruegueses Einarsen e Raknes. Adaptado e validado para ao Brasil por Christ (2012), em português, o Questionário de Atos Negativos Revisados (QAN-R) é atualmente composto por 34 itens, mede quantas vezes o respondente foi submetido a diferentes atos negativos e comportamentos potencialmente ofensivos durante os últimos seis meses como comportamentos diretos (intimidação e agressão verbal) e indiretos (difamação, isolamento social). Além de conter questões abertas, as opções de resposta em escala likert avaliam a 
frequência da exposição de situações de assédio, que vão de 1 a 5 (nunca, de vez em quando, mensalmente, semanalmente e diariamente) e permitem rastrear a possibilidade de assédio moral.

\section{Procedimentos de análise de dados}

As informações fornecidas no questionário e as respostas assinaladas no QAN-R foram registradas no banco de dados e tabulados em planilha do excel. Foram calculadas as frequências das variáveis sociodemográficas e ocupacionais dos participantes, assim como foi procedido o cálculo geral para a classificação dos docentes conforme as vivências de assédio moral ou de agressão pontual/violência psicológica.

Deste modo, para a análise da ocorrência de situações violentas foi calculada a frequência de cada item do NAQ-R, conforme agrupamento das respostas sugerido por Pooli e Monteiro (2018): "Nunca (1)" foi considerado indicativo de inexistência de violência. Para "De vez em quando (2)" atribuiu-se o significado de vivências pontuais de violência psicológica/agressões no trabalho à resposta. A ocorrência de situações de assédio moral no trabalho foi mapeada pelo agregado de "Mensalmente (3), Semanalmente (4) e Diariamente (5)", para homens e mulheres.

A frequência de "mensalmente" foi computada como indicadora de assédio para não excluir possíveis situações que, apesar de não intensamente repetitiva, apresentam potencial de gerar conseqüências negativas, em especial quando se considera grupos de trabalhadores dos quais são exigida de produtividade em ciclos mais longos do que diários e semanais, como ocorre com docentes que executam disciplinas e projetos (SOARES; OLIVEIRA, 2012; POOLI; MONTEIRO, 2018). Os itens do QAN-R foram classificados conforme as quatro categorias propostas por Hirigoyen (2017): deterioração proposital das condições de trabalho, isolamento e recusa de comunicação, atentado contra dignidade, violência verbal, física ou sexual.

\section{Achados e reflexões acerca de violências no espaço laboral investigado}

Considerando os critérios de ter sofrido repetidos e prolongados comportamentos e atos ofensivos, hostis ou agressivos, impostos de forma premeditada com o objetivo de prejudicar a dignidade e desestabilizar a saúde psíquica, 38,2\% ( $\mathrm{n}=29,15,7 \%$ mulheres e 22,5\% homens) 
relataram terem vivenciado situações de assédio moral e 15,8\% $(n=12,11,9 \%$ mulheres e 3,9\% homens) violência psicológica/agressões pontuais nos últimos seis meses.

Figura 2 - Tabela de vivências identificadas no QAN-R conforme gênero

\begin{tabular}{lcccccc}
\hline Situações identificadas no instrumento & Feminino & $\%$ & Masculino & $\%$ & Total & $\%$ \\
\hline Assédio Moral & 12 & $34 \%$ & 17 & $41,5 \%$ & 29 & $38,2 \%$ \\
Agressões pontuais/ violência psicológica & 9 & $26 \%$ & 3 & $7,3 \%$ & 12 & $15,8 \%$ \\
Não Violência & 14 & $40 \%$ & 21 & $51,2 \%$ & 35 & $46,1 \%$ \\
Total & 35 & $100 \%$ & 41 & $100,0 \%$ & 76 & $100,0 \%$ \\
\hline
\end{tabular}

Fonte: Elaborado pelos autores

Embora o grupo de professores seja o que mais relatou situações de assédio moral dentro da instituição ( $n=17 / 41,5 \%)$, vale destacar a maior proporção do grupo das professoras $(n=9$ $26 \%$ de mulheres versus $n=3-7,3 \%$ de homens) que assinalou violência psicológica por ofensas, abusos e negligências inconstantes e restritos a momentos específicos.

Conforme avaliação do QAN-R, entre as 12 (34\%) docentes assediadas, 2 estiveram na mira de outras mulheres, 2 foram alvo de homens e 7 sofreram com atos negativos perpetrados por homens e mulheres, sendo que uma não discriminou o/a agressor/a. Já entre os 17 (41,5\%) professores assediados, apenas 9 descreveram o sexo das pessoas que o assediaram, sendo que 2 foram alvos de mulheres, 3 de outros homens e 4 sofreram com atos negativos perpetrados por homens e mulheres.

O fato de o Campus universitário investigado ser composto por um número equânime de homens e mulheres, cujo exercício é semelhante em atividades desenvolvidas, carga horária e chances de ocupar cargos administrativos, revela também que mulheres têm chegado a postos de liderança na administração pública. Pode-se observar o equilíbrio de atividades desenvolvidas por professores e professoras no ensino superior (Figura 3$)^{4}$.

Embora as mulheres estejam ocupando diferentes espaços reservados historicamente aos homens, como os cargos altos de gestão e o prestigioso mundo da pesquisa, numa clara tendência de superação das cisão entre trabalho masculino e feminino, tal condição não indica a eliminação da divisão sexual do trabalho, e sim que as análises de divisão de pessoas e de tarefas devem ser refletidas de maneira específica para cada coletivo profissional, dependendo da raça/etnia e classe social.

\footnotetext{
${ }^{4}$ A frequência em porcentagem (\%) nessa tabela foi calculada considerando cada gênero (Feminino/F=35 e
} Masculino/M=41) e não o todo $(\mathrm{n}=76)$. 
Figura 3 - Tabela de atividades desenvolvidas por docentes participantes da pesquisa conforme gênero

\begin{tabular}{lcccc}
\hline & Feminino & $\%$ & Masculino & $\%$ \\
\hline Coordenação de curso de graduação & 6 & $17,1 \%$ & 8 & $19,5 \%$ \\
Ministra aula na pós-graduação & 11 & $31,4 \%$ & 12 & $29,3 \%$ \\
Orienta alunos na pós-graduação & 11 & $31,4 \%$ & 13 & $31,7 \%$ \\
Coordenação de pesquisa & 20 & $57,1 \%$ & 25 & $61,0 \%$ \\
Coordenação de extensão & 14 & $40,0 \%$ & 14 & $34,1 \%$ \\
& & & & \\
\multicolumn{1}{c}{ Perfil do trabalho } & Feminino & DP & Masculino & DP \\
\cline { 2 - 5 } & 3,6 & 1,7 & 3,5 & 1,9 \\
Média de disciplinas na graduação/semestre & 4,2 & 2,6 & 3,5 & 1,6 \\
Média de turmas na graduação/semestre & 3 & 1,2 & 3 & 3 \\
Média de orientandos na pós-graduação/semestre & 4,6 & 8,3 & 2,3 & 2,9 \\
Média de horas em atividades administrativas/semana & & & & \\
\hline
\end{tabular}

Fonte: Elaborado pelos autores

O âmbito universitário, assinalado por uma pretensa neutralidade racional científica adaptada à lógica meritocrática, acaba moldando e valorizando o distanciamento afetivo e a combatividade, comportamentos mais apropriados e desejados aos que ali exercem postos de liderança para as mulheres. Alicerçada em estratégias defensivas machistas, a disseminação da virilidade enquanto regra de conduta permite anestesiar o próprio medo e imputar sofrimento ao outro.

Para Grenier-Pezé (2004), a exploração da defesa do cinismo viril pela organização do trabalho viabiliza a imputação de violência, estratégia marcada pela construção social do masculino. Isso pode ser observado nos resultados referentes aos/às agressores/as, em que não houve preponderância de atos hostis praticados por homens.

Nunes e Tolfo (2015) salientam que não são as organizações que são neuróticas, paranóicas ou perversas, mas que seu modo de funcionamento e formato de gestão que fomentam tais comportamentos nas relações de trabalho. Assim, exigências burocráticas em demasia, ter de cumprir metas independentemente das situações reais de trabalho, lidar com falhas nas normatizações, são alguns dos fatores que acirram conflitos e animosidades entre docentes e gestão, ou mesmo entre colegas de trabalho, expressando-se em situações violentas verticais ou horizontais.

A perversa agressão organizacional perpetrada por superiores hierárquicos, mantém direta ligação com modo de funcionamento da organização do trabalho e, especialmente com sistema neoliberal. Uma possível explicação para isso está no fato de que a exploração da defesa da servidão conduz à assimilação da frenética produtividade que corrompe o ideal universitário, 
tornando as pessoas cada vez mais solitárias para acelerar e bater suas metas e cobranças o que cria um clima favorável para a ocorrência do assédio (MONTEIRO et al., 2019).

No estudo, quanto ao tipo de relação com a pessoa que cometeu a situação de assédio, as chefias/coordenação/direção atentaram contra a dignidade das mulheres em oito situações e contra os homens em cinco situações.

Relativo ao tipo ascendente foi notificada uma situação de assédio de um subordinado contra uma professora e de três estudantes contra professores. Contudo, na instituição de ensino estudada a forma mais assinalada de assédio moral foi a horizontal, sendo assinaladas 10 situações de abusos e ofensas contra as mulheres e 8 contra os homens, conforme assinalado pelos docentes estudados (Figura 4$)^{5}$.

Figura 4 - Tabela de itens mais assinalados pelos/as participantes na vivência de assédio conforme gênero

\begin{tabular}{|c|c|c|c|c|c|c|}
\hline \multirow[t]{2}{*}{ Atos frequentes } & \multicolumn{6}{|c|}{ Total } \\
\hline & $\mathrm{F}$ & $\%$ & $\mathrm{M}$ & $\%$ & Total & $\%$ \\
\hline \multicolumn{7}{|l|}{$1^{\circ}$ Fator - Deterioração proposital das condições de trabalho } \\
\hline Foi exposto a uma carga de trabalho excessiva. & 8 & $11 \%$ & 6 & $8 \%$ & 14 & $19 \%$ \\
\hline Foi obrigado a realizar um trabalho abaixo do seu nivel de competência. & 4 & $5 \%$ & 6 & $8 \%$ & 10 & $13 \%$ \\
\hline Foi solicitado a realizar tarefas despropositadas ou com prazo impossivel de ser cumprido. & 7 & $9 \%$ & 2 & $3 \%$ & 9 & $12 \%$ \\
\hline Alguém reteve informações que podem afetar o seu desempenho no trabalho. & 4 & $5 \%$ & 4 & $5 \%$ & 8 & $11 \%$ \\
\hline \multicolumn{7}{|l|}{$2^{\circ}$ Fator - Isolamento e recusa de comunicação } \\
\hline Suas opiniões e pontos de vista foram ignorados. & 8 & $11 \%$ & 6 & $8 \%$ & 14 & $19 \%$ \\
\hline Foi ignorado, excluído ou "colocado na geladeira". & 7 & $9 \%$ & 5 & $7 \%$ & 12 & $16 \%$ \\
\hline Foi ignorado ou foi recebido com uma reação hostil quando tentou uma aproximação. & 6 & $8 \%$ & 2 & $3 \%$ & 8 & $11 \%$ \\
\hline \multicolumn{7}{|l|}{$3^{\circ}$ Fator - Atentado contra a dignidade } \\
\hline $\begin{array}{l}\text { Foram feitos comentários ofensivos sobre a sua pessoa (isto é, sobre hábitos ou suas origens), } \\
\text { suas atitudes ou sobre sua vida privada. }\end{array}$ & 6 & $8 \%$ & 5 & $7 \%$ & 11 & $15 \%$ \\
\hline Espalharam boatos ou rumores sobre você. & 4 & $5 \%$ & 7 & $9 \%$ & 11 & $15 \%$ \\
\hline Houve tentativas de encontrar erros em suas tarefas. & 6 & $8 \%$ & 3 & $4 \%$ & 9 & $12 \%$ \\
\hline \multicolumn{7}{|l|}{$4^{\circ}$ Fator - Violência verbal, física ou sexual } \\
\hline $\begin{array}{l}\text { Gritaram com você ou você foi alvo de agressividade gratuita (ou demonstraram ter raiva de } \\
\text { você). }\end{array}$ & 5 & $7 \%$ & 4 & $5 \%$ & 9 & $12 \%$ \\
\hline
\end{tabular}

Fonte: Elaborado pelos autores

A classificação dos atos negativos mais frequentes cometidos contra os docentes permitiu a análise do QAN-R por diferentes aspectos que compõem os atos negativos, conforme proposto por Hirigoyen (2017).

O fator "deterioração proposital das condições de trabalho", que inclui ações que fazem o outro se sentir incompetente e ocorre principalmente de forma vertical, pelo superior

${ }^{5}$ Optou-se por incluir apenas os itens com frequência com ocorrência superior a $10 \%$. A porcentagem foi calculada considerando todos os participantes $(\mathrm{n}=76)$.

RPGE- Revista on line de Política e Gestão Educacional, Araraquara, v. 24, n. esp. 3, p. 1841-1855, dez. 2020. e-ISSN:1519-9029 
hierárquico, evidenciou a imposição de sobrecarga de trabalho (19\%), havendo uma maior proporção do grupo feminino em realizar uma carga maior de tarefas $(11 \%)$ com relação aos homens (8\%), sugerindo a luta ainda empreendida pelas mulheres para se mostrarem capazes e valorizadas, conforme a lógica produtivista.

A avaliação quantitativa como norma para ser reconhecida é naturalizada e propagada no contexto universitário, se relaciona ao ideário privatista de produção, não importando as condições de trabalho precárias para a realização de tarefas, sendo comum as mulheres levarem trabalho para casa, já que acumulam mais turmas de graduação e gastam mais tempo em atividades administrativas do que os homens (Figura 3 ).

A suposta aceitação em cumprir múltiplas atividades, em curto prazo de tempo, desalinhadas com sua função e sem as informações/recursos necessários, não passa impune pela subjetividade pressionada moralmente (BARRETO; HELOANI, 2014). A adesão à ideologia da excelência incita o uso das estratégias do individualismo, da aceleração e da servidão, podendo adoecer e normalizar a violência (SILVA; RUZA, 2018). Neste sentido, o assédio moral não pode ser analisado em descompasso da cultura organizacional tolerante a condutas agressivas e hostis.

O fator "isolamento e recusa de comunicação", normalmente praticado parte da chefia ou colegas, é composto por ações ou comportamentos que excluem e boicotam os pares, tais como evitar contato pessoal e interromper constantemente a fala do outro. Entre os docentes pesquisados, 19\% afirmaram terem sido ignorados em suas opiniões, situação que contribui para o isolamento, conformando um espaço de solidão propício para o silenciamento.

Segundo Ferreira (2016), em muitos dos casos os colegas se omitem e se calam por temor de serem as próximas vítimas, encaram a hostilidade como algo próprio do ambiente de trabalho, desdenhando o sofrimento alheio. Por sua vez, não encontrar respaldo nos colegas de trabalho acaba agravando o sofrimento e a chance de do assédio continuar acontecendo. A falta de relações solidárias e cooperativas priva o indivíduo de se valer de estratégias coletivas defensivas capazes de minimizar o sofrer, sendo comum o uso da repressão, num esforço do ego em se adaptar e reprimir o sofrimento, ficando ainda mais subserviente e sujeito a agressões.

Geralmente proferido por colegas, de forma horizontal, o "atentado contra a dignidade" é feito por insultos, desprezo e desqualificação da vida pessoal, zombaria da nacionalidade e origem da pessoa. Na pesquisa observou-se a predominância de comentários ofensivos (15\%) e boatos sobre a vida particular (15\%), indicando a intromissão e tentativa desmedida de controle e regulação da vida, até mesmo fora do trabalho. 
Quando o assédio já se mostra tipificado, instala-se a violência verbal, física e sexual, vista nas perseguições, ameaças ou agressões físicas ou verbais, sugestões sexuais, xingamentos, gritos, seja por meio de ligações telefônicas, mensagens ou e-mails, dentro e fora do espaço laboral. Entre os docentes, o item mais assinado de violência expressa foi ter sido alvo de gritos e raiva $(12 \%, 7 \%$ mulheres e $5 \%$ homens $)$.

Já na avaliação da ocorrência de violência psicológica, rastreada por atos negativos sofridos sem a constância e repetição necessárias para a categorização do assédio moral, foram reportadas por maior contingente de trabalhadores e trabalhadoras a presença de situações que colaboram para a deterioração proposital das condições de trabalho, com comportamentos deliberados de isolamento e recusa de comunicação, afetação à dignidade e até mesmo violência verbal e física (Figura 5)

Figura 5 - Tabela de itens mais relatados pelos/as docentes na vivência não caracterizada como assédio conforme gênero

\begin{tabular}{|c|c|c|c|c|c|c|}
\hline \multirow[t]{2}{*}{ Atos Vivenciados } & \multicolumn{6}{|c|}{ Total } \\
\hline & F & $\%$ & $\mathrm{M}$ & $\%$ & Total & $\%$ \\
\hline $1^{\circ}$ Fator - Deterioração proposital das condições de trabalho & & & & & & \\
\hline Alguém reteve informações que podem afetar o seu desempenho no trabalho. & 17 & 2270 & 10 & $17>0$ & 30 & 3900 \\
\hline Foi solicitado a realizar tarefas despropositadas ou com prazo impossível de ser cumprido. & 10 & $13 \%$ & 9 & $12 \%$ & 19 & $25 \%$ \\
\hline Foi exposto a uma carga de trabalho excessiva. & 9 & $12 \%$ & 8 & $11 \%$ & 17 & $23 \%$ \\
\hline $2^{\circ}$ Fator - Isolamento e recusa de comunicação & & & & & & \\
\hline Suas opiniões e pontos de vista foram ignorados. & 14 & $18 \%$ & 9 & $12 \%$ & 23 & $31 \%$ \\
\hline Foi ignorado ou foi recebido com uma reação hostil quando tentou uma aproximação. & 5 & $7 \%$ & 9 & $12 \%$ & 14 & $19 \%$ \\
\hline Foi ignorado, excluído ou "colocado na geladeira". & 6 & $8 \%$ & 3 & $4 \%$ & 9 & $12 \%$ \\
\hline $3^{\circ}$ Fator - Atentado contra a dignidade & & & & & & \\
\hline Houve tentativas de encontrar erros em suas tarefas. & 7 & $9 \%$ & 12 & $16 \%$ & 19 & $25 \%$ \\
\hline $\begin{array}{l}\text { Foram feitos comentários ofensivos sobre a sua pessoa (isto é, sobre hábitos seus ou suas } \\
\text { origens), suas atitudes ou sobre sua vida privada. }\end{array}$ & 9 & $12 \%$ & 9 & $12 \%$ & 18 & $24 \%$ \\
\hline Foram feitas alegações contra você. & 10 & $13 \%$ & 8 & $11 \%$ & 18 & $24 \%$ \\
\hline $\begin{array}{l}4^{\circ} \text { Fator - Violência verbal, física ou sexual } \\
\text { Gritaram com você ou você foi alvo de agressividade gratuita (ou demonstraram ter raiva } \\
\text { de você). }\end{array}$ & 9 & $12 \%$ & 4 & $5 \%$ & 13 & $17 \%$ \\
\hline Recebeu mensagens, telefonemas ou correio eletrônicos contendo & 6 & $8 \%$ & 7 & $9 \%$ & 13 & $17 \%$ \\
\hline $\begin{array}{l}\text { Foi alvo de comportamentos intimidativos tais como "apontar o dedo", invasão de seu } \\
\text { espaço pessoal, empurrões, bloqueio de seu caminho ou passagem. }\end{array}$ & 3 & $4 \%$ & 5 & $7 \%$ & 8 & $11 \%$ \\
\hline
\end{tabular}

Fonte: Elaborado pelos autores

Importante apontar que $60 \%(n=21)$ das professoras apresentaram escore compatível com vivência de assédio/violência na instituição em seus últimos seis meses de trabalho $(\mathrm{n}=12$,

${ }^{6}$ Para fins de análises neste artigo, optou-se por incluir apenas os três itens de cada categoria do instrumento que apresentaram as maiores frequência de relato. A porcentagem foi calculada considerando todos os participantes $(n=76)$. Foram contabilizados todos os atos assinalados como "De vez em quando" (2), mesmo aqueles respondidos por participantes que se enquadram no assédio pela frequência alta em outros itens.

RPGE- Revista on line de Política e Gestão Educacional, Araraquara, v. 24, n. esp. 3, p. 1841-1855, dez. 2020. e-ISSN:1519-9029 
$34 \%$ assédio moral e $n=9,26 \%$ violência/agressões pontuais). Entre os professores, 48,7\% $(\mathrm{n}=20)$ foram alvo de assédio/violência $(\mathrm{n}=3,3 \%$ para assédio e $\mathrm{n}=17,41,4 \%$ para violência/agressões pontuais).

Em que pese o grande número de mulheres e homens que relataram maltrato no trabalho, apenas 35 professoras mulheres e 9 homens afirmaram terem percebido os atos negativos sofridos como assédio moral, havendo discrepância entre a percepção subjetiva e as respostas assinaladas.

Levando em conta o silenciamento devido ao temor de punições ou represálias, ou mesmo de estimular com a denúncia o acirramento do assédio e agressões, é necessário alertar para a submissão banalização dos atos negativos viris na instituição, assumidos e perpetrados por homens e mulheres, especialmente quando se estabelece como regra consensual a servidão voluntária frente aos impedimentos de transformar o trabalho e o sofrer.

\section{Considerações finais}

Bastante evidente na iniciativa privada, o assédio moral no serviço público pode perdurar e ser devastador à saúde mental. Em tempos de sucateamento da universidade pública, é de suma importância que se compreenda a relação entre Estado mínimo e o avanço da naturalização de práticas violentas, insidiosas, baseadas na gestão gerencialista para o aumento da produção. Como alertam Glina e Soboll (2012, p. 279), "não se pode esquecer ainda, que o assédio moral no trabalho é fruto de um momento histórico e de um contexto social e econômico, definidores da forma de organização do trabalho e do desenho das relações humanas neste contexto".

Embora não deva ser confundida com o assédio organizacional, caracterizado pelo entranhamento da violência nas políticas de gestão que toleram a agressividade e incentivam a competição (SOBOLL, 2008), os dados alertam para o risco da gestão se utilizar de ameaças e medo para obter sucesso, tendo como conduta consensual implícita a validação da ideologia viril. Posto que na servidão voluntária o servidor aliena sua vontade e desejo aos projetos e valores organizacionais, a adaptação normótica a práticas violentas e perversas contribui para a ocorrência de assédio moral.

Logo, para o rompimento com a situação de assédio moral é preciso considerar como se dão as relações sociais, simbólicas e de gênero que favorecem a vivência do medo e, consequentemente, a manutenção da situação de violência por meio do silenciamento. Destarte, a criação de um espaço de escuta e acolhimento pode auxiliar na elaboração dos atos sofridos, 
bem como na retomada do sentido de seu fazer e na retomada do próprio desejo. Como sinalizam Monteiro et al. (2019), o sofrimento funciona como um alerta que mobiliza o sujeito, podendo ou não culminar em patologia, sendo determinante o modo como será conduzido. Por isso, as políticas institucionais precisam de atenta observação para não alicerçarem um sistema violento como lógica de trabalho.

Embora este estudo tenha por limitação sua realização em um pequeno coletivo de docentes, os resultados permitem apontar para a necessidade de políticas educacionais que garantam o estabelecimento de laços de cooperação, confiança e respeito entre colegas, chefias e gêneros, em consonância com a Convenção 190 da Organização Internacional do Trabalho (2019). Para isso, é preciso que o espaço universitário reconheça, promova e proteja os vínculos democráticos, de forma a desconstruir a lógica de controle produtivo despida de ética e de vida com trabalho criativo.

AGRADECIMENTOS: O presente trabalho foi realizado com apoio da Coordenação de Aperfeiçoamento de Pessoal de Nível Superior - Brasil (CAPES) - Código de Financiamento 001. Recebeu apoio financeiro da Fundação Universidade Federal de Mato Grosso do Sul UFMS, Brasil e do Conselho Nacional de Desenvolvimento Científico e Tecnológico (CNPq), em bolsas PIBIC e PIBIC-AF.

\section{REFERÊNCIAS}

BARRETO, M.; HELOANI, R. O assédio moral como instrumento de gerenciamento. In: MERLO A. R. C.; BOTTEGA, C. G.; PEREZ, K. V. (Org.). Atenção à saúde mental do trabalhador: sofrimento e transtornos psíquicos relacionados ao trabalho. Porto Alegre: Evangraf, 2014. p. 52-74.

CHRIST, H. D. Estudo de adaptação e fidedignidade do Questionário de Atos Negativos Revisado (QAN-R) para o português do Brasil. Orientador: Gabriel José Chittó Gauer. 2012. 71 f. Dissertação (Mestrado em Psicologia Clínica) - Pontifícia Universidade Católica do Rio Grande do Sul, Porto Alegre, 2012. Disponível em: http://repositorio.pucrs.br/dspace/bitstream/10923/4932/1/00022436210-Texto\%2bCompleto0.pdf. Acesso em: 5 jun. 2020.

DEJOURS, C. A banalização da injustiça social. Trad. Luiz Alberto Monjardim. Rio de Janeiro: Fundação Getúlio Vargas, 2006.

DEJOURS, C. Psicodinâmica do trabalho na pós-modernidade. In: MENDES, A. M; LIMA, S. C. C; FACAS, E. P. (Org.). Diálogos em psicodinâmica do trabalho. Brasília: Paralelo 15, 2007. p. 13-26. 
FERREIRA, J. B. Quantos anos de solidão? Violência, assédio moral e paralisia das formas de vida no trabalho. In: FARAH, B. L. (Org). Assédio moral organizacional: novas modalidades do sofrimento psíquico nas empresas contemporâneas. São Paulo: LTr, 2016. p. 111-119.

GLINA, D. M. R.; SOBOLL, L. A. Intervenções em assédio moral no trabalho: uma revisão da literatura. Rev. bras. saúde ocup., São Paulo, v. 37, n. 126, p. 269-283, dez. 2012.

Disponível em: https://www.scielo.br/pdf/rbso/v37n126/a08v37n126.pdf. Acesso em: 29 set. 2020.

GRAETZ, C. F. O campo científico, os conflitos e relações de poder no trabalho de professores de uma universidade pública. Orientador: Eduardo Pinto e Silva. 2013. $120 \mathrm{f}$. Dissertação (Mestrado em Educação) - Universidade Federal de São Carlos, São Carlos, 2013. Disponível em: https://repositorio.ufscar.br/handle/ufscar/2647?show=full. Acesso em: 27 ago. 2020.

GRENIER-PEZE, M. Forclusão do feminino na organização do trabalho: um assédio de gênero. Rev. Prod., São Paulo, v. 14, n. 3, p. 6-13, dez. 2004. Disponível em: https://www.scielo.br/pdf/prod/v14n3/v14n3a01.pdf. Acesso em: 5 out. 2020.

HELOANI, R; BARRETO, M. Aspectos do trabalho relacionados à saúde mental: assédio moral e violência psicológica. In: GLINA, D. B. R.; ROCHA, L. E. (Org.). Saúde mental no trabalho: da teoria à prática. São Paulo: Roca, 2010. p. 31-48.

HIRIGOYEN, M. Mal-estar no trabalho: redefinindo o assédio moral. 4. ed. Trad. R. Janowitzer. Rio de Janeiro: Bertrand Brasil, 2017.

KERGOAT, D. Divisão sexual do trabalho e relações sociais de sexo. In: HIRATA, H. et al. (Org.). Dicionário crítico do feminismo. São Paulo: Editora UNESP, 2009. p. 67-75.

MEDEIROS, S. N.; MARTINS, S. R.; MENDES, A. M. Sofrimento e defesa: análise psicodinâmica do trabalho de monitoramento aéreo de trânsito. Trivum, Rio de Janeiro, v. 9, n. 1, p. 74-90, jun. 2017. Disponível em:

http://pepsic.bvsalud.org/pdf/trivium/v9n1/v9n1a08.pdf. Acesso em: 22 jan. 2018.

MENDES, A. M. Novas formas de organização do trabalho, ação dos trabalhadores e patologias sociais. In: MENDES, A. M. (Org.). Psicodinâmica do trabalho: teoria, método e pesquisas. São Paulo: Casa do Psicólogo, 2007. p. 49-61.

MONTEIRO, J. K. et al. Contribuições da psicodinâmica e clínica do trabalho ao enfrentamento do assédio moral no trabalho. In: MONTEIRO et al. (Org). Trabalho que adoece: resistências teóricas e práticas. Porto Alegre: Editora Fi, 2019. p. 79-116.

MOREIRA, A. F. A cultura da performatividade e a avaliação da pós-graduação em educação no Brasil. Educ. Rev., Belo Horizonte, v. 25, n. 3, p. 23-42, dez. 2009. Disponível em: https://www.scielo.br/pdf/edur/v25n3/03.pdf. Acesso em: 27 ago. 2020.

NUNES, T. S.; TOLFO, S. R. O assédio moral no contexto universitário: uma discussão necessária. Rev. de ciênc. da adm., Florianópolis, v. 17, n. 41, p. 21-36, 2015. Disponível em: https://www.redalyc.org/articulo.oa?id=2735/273537756003. Acesso em: 27 fev. 2020. 
ORGANIZAÇÃO INTERNACIONAL DO TRABALHO. C190: violence and harassment convention. 2019 (no. 190). Disponível em:

https://www.ilo.org/dyn/normlex/en/f?p=1000:12100:0::NO::P12100_INSTRUMENT_ID,P1 2100_LANG_CODE:3999810,en:NO Acesso em: 2 maio 2020.

POOLI, A. M; MONTEIRO, J. K. Assédio moral no judiciário: prevalência e repercussões na saúde dos trabalhadores. Revista psic.: org. e trab., Florianópolis, v. 18, n. 2, p. 346-353, abr./jun. 2018. Disponível em: http://pepsic.bvsalud.org/pdf/rpot/v18n2/v18n2a02.pdf. Acesso em: 19 set. 2020.

SILVA, E. P; RUZA, F. M. A malversação do reconhecimento no trabalho docente precarizado e intensificado. Trabalho (En)Cena, Palmas, v. 3, n. 2, p. 3-16, 2018. Disponível em: https://sistemas.uft.edu.br/periodicos/index.php/encena/article/view/4981/13230. Acesso em 27 ago. 2020.

SOARES, A.; OLIVEIRA, J. A. Assédio moral no trabalho. Rev. bras. saúde ocup., São Paulo, v. 37, n. 126, p. 195-202, dez. 2012. Disponível em:

https://www.scielo.br/pdf/rbso/v37n126/a02v37n126.pdf. Acesso em: 30 set. 2020.

SOBOLL, L. A. P. Assédio moral/organizacional: uma análise da organização do trabalho. São Paulo: Casa do Psicólogo, 2008.

\section{Como referenciar este artigo}

FIGUEIREDO, V. C. N.; SILVA, Q. E. F.; SANTANA, F. A. L. Assédio moral e gênero na universidade pública: ressonâncias do produtivismo no trabalho docente. Revista on line de Política e Gestão Educacional, Araraquara, v. 24, n. esp. 3, p. 1841-1855, dez. 2020. eISSN:1519-9029. DOI: https://doi.org/10.22633/rpge.v24iesp3.14291

Submetido em: 10/08/2020

Revisões requeridas: $20 / 10 / 2020$

Aprovado em: 05/11/2020

Publicado em: 30/11/2020 